\title{
Taking the Measure of Things:
}

\section{The Role of Measurement in EU Trade}

\author{
M. Ali Choudhary ${ }^{q^{*}}$, Paul Temple ${ }^{\text {q }}$, Lei Zhao ",
}

Keywords: Intra-industry trade; product differentiation; measurement; standards

JEL classification: F12; F14; F15; L1; L60

This version July 2010

\footnotetext{
I Department of Economics, University of Surrey, Guildford, GU2 7XH, UK

* Research Department, State Bank of Pakistan, I.I. Chundrigar Rd, Karachi, Pakistan

‡Corresponding author: p.temple@surrey.ac.uk
} 


\title{
Taking the Measure of Things:
}

\section{The Role of Measurement in EU Trade}

\begin{abstract}
In this paper theoretical and empirical models of intra-industry trade are developed in which economic activities, based on measurement and an associated measurement infrastructure, play a role in creating product variety. The paper discusses how the measurement infrastructure which includes institutions conducting metrological research and standard setting organization reduces transactions costs, especially in markets where differences in product characteristics are important. The theoretical analysis focuses on the public good characteristics of the measurement infrastructure, considering how the infrastructure impacts upon trade in a model based upon product differentiation under monopolistic competition. In the econometric analysis, indicators of the strength of the infrastructure within the EU, both across industries and across countries, suggest that measurement activities are important in determining the extent of bi-lateral EU intra-industry trade. Despite many common elements in the measurement infrastructure across the EU, there is also some evidence of differential access to the infrastructure among EU members.
\end{abstract}

July 2011 


\section{Introduction}

Over the last two decades, economics has developed theories in which product differentiation provides an important element in the underlying mechanisms driving trade, growth, and location. In the theory of international trade, the creation of variety leads to intra-industry trade; in endogenous growth models increased varieties of intermediate inputs generates productivity advance in downstream industries, a process which may also lead to geographical agglomeration. Theoretical analysis in these areas is typically based upon models of monopolistic competition, where increasing returns prevail and market size matters in the generation of product variety. However the nature of the costs associated with product differentiation are rarely considered in any detail. This paper develops this element of such models by introducing measurement as an important channel for generating variety.

Successful product differentiation by firms is often founded upon distinctive intrinsic product characteristics, requiring that these characteristics be either directly observable, e.g. the colour of a table, or measured in ways that customers are able to comprehend, such as the table's physical dimensions, where understanding is aided by an agreed standard unit of measurement. As products become more complex in terms of characteristics, buyers and sellers are likely to find such standards increasingly helpful. If for example the table-top is constructed of a novel material, its performance characteristics - e.g. colour fastness, reaction to heat or sunlight, durability - may be subject to uncertainty and the seller's claims difficult to verify. Indeed, for advanced manufacturing technologies, Tassey (2000 p.589) notes "a range of measurement and test method standards provide information, which, by virtue of being universally accepted, greatly reduce transaction costs between buyer and seller." Industrial standards relating to measurement and associated tests belong to what we term in this paper as the "measurement infrastructure" of an economy, the various institutions which link the science of metrology to the actual use of measures by industry and society and which typically require complementary investments at the level of the firm or household and the use of instruments. The paper considers the relationship between this measurement infrastructure 
and the creation of product variety, developing both theoretical and empirical models of product differentiation and intra-industry trade. The empirical analysis is based on industrial and trade data relating to the European Union (EU), where standard development has increasingly taken a panEuropean form.

The paper is organised as follows. The following section describes the nature of measurement infrastructures and discusses their role in modern economies. Section 3 then shows how the concept of a measurement infrastructure can be embedded in a model of intra-industry trade. Section 4 discusses some econometric models based on the preceding analysis and presents the results. Section 5 summarizes and concludes.

\section{The Economic Role of Measurement}

Much of the recent literature in growth economics has emphasised the role of knowledge, the externalities it creates, and the potential for active policy, especially in the areas of science and technology. However, effective policy intervention needs an understanding of the mechanisms which generate and link different types of knowledge, permitting assessments of the nature of the externalities involved and of how they are captured by institutions and firms. The basic premise of this paper is that the concept of measurement, its associated institutions, and the economic activity which depend on them, provide important insights into the linkages between the creation of knowledge and its utilisation in the form of appropriable technologies, especially those which result in product differentiation. An important element in this latter process is the development of a codified knowledge base in the form of industrial standards. Moreover, the generic character of measurement and its pervasive use, especially in the production and marketing of manufactured goods, make the public good aspect of measurement activity important.

In a substantial review of the economics of measurement, Swann (1999) divides measurement activities in an economy into three main functional types - research, the development of measurement tools and infrastructure (e.g. the means for monitoring the environment or the 
health impact of nano-technologies), and the operational use of tools and techniques for 'day to day' measurement - in both firms and households. Our main concern in this paper is with the mechanisms through which metrological research and the associated development of measurement tools impacts upon the ability of individual firms to differentiate their output. In advanced economies, a large part of basic metrological research is conducted by so-called National Metrology Institutes (NMIs). Examples of such bodies include the Germany's Physikalisch-Technische Bundesanstalt (PTB) or the UK's National Physical Laboratory (NPL). Typically financed in part by the government, they conduct not only basic research and measurement tool development, but also perform other activities which link the research output to industry and society. At both PTB and NPL, much of the research is carried co-operatively with private industry. Figure 1 is intended to suggest how the knowledge generated by such NMIs may diffuse into an economy more widely. Four key processes are highlighted: standardisation, direct service provision, the accreditation of private sector laboratories and legal metrology (which underpins such areas as weights and measures and, increasingly, environmental protection). Patterns taken by the measurement infrastructure of course vary between countries, and the function of research may be undertaken by a different body from the regulatory function provided by legal metrology, or the accreditation of private calibration and testing laboratories ${ }^{1}$. In this paper however, we concentrate on the role of measurement in the EU, where measurement forms a coherent set of activities partly defined by various national institutions but also at the regional (or supra-national) levels ${ }^{2}$, a fact which raises questions about the extent of EU integration considered later in section 4.

\section{\{FIGURE 1 about here\}}

\footnotetext{
${ }^{1}$ In the US for example. there is greater pluralism and no single national body, although the National Institute of Standards and Technology (NIST) operates within the Department of Commerce and is charged with promoting "US innovation and industrial competitiveness by advancing measurement science standards and technology in ways that enhance economic security" http://www.nist.gov/public_affairs/general2.htm\#Whatwedo

2 The Measurement Instrument Directive for example provides a legal requirement for measurement standardization across the EU. The Commission also directly supports research in measurement and testing on a cross-sectoral and cross-country basis and provides assistance to clubs and networks such as EUROMET and EURACHEM (Williams 2002). Pan-European institutions are also important in the creation of standards, as discussed further below
} 
In addition to their research and development role, NMIs are often heavily involved in the creation of industrial standards, a process particularly important from the point of view of this paper. NMIs are involved in standardisation in a number of ways. These include not only developing and maintaining the base of primary and reference standards used for purposes of traceability, but also providing input into the development of industrial standards produced by the technical committees of National Standards Bodies (such as the Deutsche Institut fur Norming (DIN) in Germany or the British Standard Institution (BSI), and, increasingly by international standards agencies, such as the International Organisation for Standardisation (ISO) or the International Telecommunications Union (ITU). In Europe, standardisation has now largely taken a panEuropean form, and the European Committee for Standardisation (CEN) for example currently represents 30 member countries each of which adopts CEN standards in its own economy ${ }^{1}$.

Standards may fulfil any of a number of functions, including reduction in variety to achieve economies of scale, the promotion of inter-operability and network externalities, and the definition of minimum qualities, which may be important in the context of regulation. The theoretical economic literature on standards (Farrell and Saloner [1985] Katz and Shapiro [1985]), as well as the more well known case studies (e.g. David 1975), have concentrated on understanding the implications of individual standards, and especially the compatibility or inter-operability function, in circumstances where this function defines a 'network' which may operate across many individual firms. The literature distinguishes between de facto standards, created through the development of proprietary technology and which may involve a standards 'race' between competing proprietary technologies (e.g. Besen and Farrell [1994]), and de jure standards which emerge as the result of the deliberation and eventual consensus of a technical committee. Important recent contributions have

\footnotetext{
${ }^{1}$ Some of the standards so developed support European legislation and regulation and conformity to a standard a form of compliance. Other pan-European standardisation bodies specialise in electro-technical standardisation (CENELEC) and in information and communication technologies (ETSI). The increasing internationalisation of standards is discussed in DTI (2005).
} 
investigated the performance attributes of both types of process (e.g. Farell and Saloner 1988; Simcoe 2008; Farrell and Simcoe 2009). For an extensive review of the economics of standards see Swann (2000).

Measurement is likely of course to be integral to the specifications required for interoperability and consequential network effects. Here the literature suggests a public good effect in cases of positive adoption costs, where early adopters of a standard create support the development costs on which later users may free-ride. Moreover fixed costs attached to development may mean that early adopters are unwilling to support development. The public good character is not of course limited to this effect alone, but as recognised by Kindleberger (1984), standards of many kinds provide a "strong" kind of public good by establishing a network such that "the more producers and consumers use a given standard, the more each gains from use by others through gains in comparability and interchangeability" (Kindelberger 1984, p. 377). Measurement is of course central to the whole concept of comparability, as is the credibility that attaches to publicly available standards.

In practice, actual standards documents may fulfil several of the functions described above, while in addition providing useful codified technological information. While in general standards serve to reduce the transactions costs of using the market and tend to promote product differentiation, it should however be pointed out that measurement may also serve as an input into the creation of variety reducing standards with a contrary effect. Moreover, measurement infrastructure may also contribute to the development of interfaces in 'technology systems' where measurement enables lower cost verification, which permits market based specialization along supply chains, and which may also thereby stimulate product diversity ${ }^{1}$.

Figure 1 suggests that much of the domestic knowledge flow between the NMIs and industry is mediated by instrument manufacturers and technical business services which carry out calibrations, test equipment and so on. UK evidence shows that together these types of business are

\footnotetext{
${ }^{11}$ We are grateful to an anonymous referee for pointing out the relevance of measurement for supply-chain interfaces
} 
the dominant purchasers of direct services from the NMIs (King et al. 2005) while the private laboratories are an important intermediary for small and medium sized companies (Temple and Williams 2002).

One way of making the linkages depicted in Figure 1 more concrete is suggested by Swann (1999) who draws attention to the relationship between measurement and product differentiation. As Swann puts it, cumulative experience and learning in metrology and the associated development of measurement tools generates a "common pool of feasible measurements". The size of this pool helps determine the size of another - "the pool of measurable product characteristics." A sub-set of this latter is the pool of feasible product characteristics (Swann 1999, p.9) from which producers can draw to make actual products available to customers. Swann also argues that much product innovation can be thought of not simply in terms of the improvement of given product characteristics but also in terms of novel product characteristics, giving "a combinatorial character to product innovation. How many variants can be produced depends (very roughly speaking) on the number of characteristics that can be combined" (ibid p. 19).

A similar perspective to that of Swann has been provided by Tassey (e.g. 2000, 2004), who distinguishes between three types of knowledge base. In addition to the proprietary knowledge base of individual firms, Tassey also defines an industry's generic technology base, and a set of what he terms "infratechnologies" that "provide a varied and critical infrastructure to support development of the generic technology and subsequent market applications" (Tassey 2000, p.589). These infratechnologies consist of "measurement and test methods, interface standards, scientific and engineering databases, and artefacts such as standard reference materials." This knowledge base frequently takes the specific form of what Tassey calls "non-product" based standards, which play a key role in supporting the generic knowledge base of (perhaps) several industries ${ }^{1}$.

\footnotetext{
${ }^{1}$ In the form of standards he argues they have a strong public good element. Moreover among the set of infratechnologies, Tassey gives an important place to measurement, citing a 1998 NIST study which estimated that the US semi-conductor industry would spend $\$ 5.5$ billion on measurement, "much of which would end up as industry standards" (Tassey 2005, p109, footnote 11).
} 
It is perhaps useful to illustrate the underpinning and generic role of measurement in enabling capabilities associated with the characteristics of products. Thermal conductivity is a fundamental property of materials and a key product characteristic in a range of industries, e.g. for catering equipment or textiles among consumer products, or in construction, for building materials. The NPL web-site (FAQ) lists 18 standard documents for measuring the thermal conductivity of different construction materials, refractories, and plastics ${ }^{1}$.

The importance of measurement as an enabling technology can be explored empirically in many different ways - for example by directly linking it to productivity and growth. Temple and Williams (2002) for example, cite a number of studies which have attempted to link measurement research with productivity at an aggregate/macro-level. At a more micro level however, a recent study commissioned by NIST links measurement directly to productivity improvements in the U.S. semi-conductor industry over the period 1996-2006 ${ }^{2}$ (NIST 2007). Here however we consider a more aggregative approach suggested by the link between measurement and product variety.

The discussion so far suggests that two types of metric may be useful in gauging the differential importance of measurement between sectors or economies. The first is through the production and use of measuring instruments in an economy. ${ }^{3}$ Here, Williams (2002) estimates that production in the sector amounts to about 1\% of total (pre-enlargement) EU industrial production. However he observes that this ratio varies considerably by country - ranging from $0.12 \%$ in Portugal to $2.04 \%$ in Sweden. More important than production (which will reflect specialisation in these sectors) is the extent of consumption of instruments. Figure 2 shows a plot of both production and consumption of instruments for EU economies, expressed as a proportion of industrial output. It can be seen that the use of instruments is closely related to the location of instrument production,

\footnotetext{
${ }^{1}$ http://www.npl.co.uk/server.php?show=ConWebDoc.2136, accessed 18 July 2010

2 It suggests an internal rate of return on investments made between 1996 and 2006 and accruing between 1997 and 2011 of $67 \%$

${ }^{3}$ One element of the second tier - testing facilities - is not distinguishable even at the 4-digit NACE coding from other types of business service.
} 
although the larger consumers do appear to have something of a comparative advantage and be net exporters ${ }^{1}$.

\{FIGURE 2 about here\}

Detailed data on the extent of instrument use within sectors are not available for the EU on a country by country basis. However we can make use of the close association between measurement and industrial standards made publicly available through the national standards bodies (NSBs) discussed above. In the current context the existence of a catalogue of standards which can be counted provides a means of measuring the 'size' of their impact - a methodology used initially in Swann et al (1996) and considerably extended by Blind in a series of important studies (for example Blind 2001, 2004), and in the specific context of German-UK trade by Blind and Jungmittag (2005). This paper further develops the approach by considering a sub-set of 'measurement related' standards. The extent to which these latter figure against all standards in the catalogue of the BSI available at end 2003 is shown in Figure 3, using the PERINORMC search tool. It shows that a total of nearly 25,000 standards were available to UK producers. Counts of the abstracts of these documents revealed that around a quarter of these $(6,600)$ included a reference to both a test procedure and measurement (which we term the 'narrow' count of measurement standards) while two-thirds $(16,800)$ contained either or both (the 'broad' count of measurement standards). Either way it seems reasonable to conclude that standards are an important part of the measurement infrastructure through which the work of the NMIs is distributed to the economy generally, and which makes increased private expenditures on measurement profitable.

\footnotetext{
${ }^{1}$ One tentative explanation - but beyond the scope of this paper - is that geographically bounded technological spill-over effects (emanating in part from the NMIs) may be important in either/or the consumption and production of instruments. Below we use the overall cross-country pattern of instrument consumption/use as a possible factor in an econometric model of the factors determining intra-industry trade.
} 
\{FIGURE 3 about here\}

Figure 3 also shows comparable counts for end 1985 and indicates that while there has been strong growth in the size of the total standards stock (5.6\% per annum over the period), this has been roughly similar for 'measurement related' standards. Importantly much of this growth over the past two decades is attributable to the harmonisation of standards within the EU (see DTI 2005), and of course all the standards available from the BSI catalogue are available to producers anywhere - so that the size of the catalogue cannot realistically be employed as a country characteristic. However, we were able to count the size of the catalogue by industry and hence provide an industry characteristic for the empirical models considered below in section 4. Table 1 shows the distribution of measurement related standards for 2002 for the 22 sectors used. It can be seen from the table that that the use of standards varies considerably across sectors - with the main users being found in the engineering industries which rely heavily on the products of what Nelson (1993) has called "systems technologies"; where products depend in their turn on the ability of individual firms to utilise the market to source components. In other measurement intensive technologies, e.g. in the chemical industries, access to components is perhaps less critical, and so, despite the large amounts spent on $\mathrm{R} \& \mathrm{D}$, there will be less demand for publicly created standards which lower transactions costs, even though in-house measurement may be considerable.

\section{\{TABLE 1 about here\}}

In the empirical analysis reported below we make use of both types of metric described above, using them as proxies for the strength of the technology infrastructure as this relates to different industries and/or economies. However, it is possible that both standards and varieties are a joint outcome of technology life cycles, with mature technologies - which are well understood generating both more standards and more variety. Since this possibility is important for our 
interpretation of the regression analysis below, we return to this point our concluding section. ${ }^{1}$ Here however we note that the count we use relates to measurement related standards (rather than all standards) and which may well develop relatively early in technology cycles, prior to the emergence of a dominant design (Utterback and Abernathy 1975).

In order to generate specific hypotheses regarding the role of measurement and standards in generating international trade, we next develop a model of intra-industry trade which specifically bases itself on the public good characteristics of measurement standards described above. The literature suggests a number of possible avenues for understanding product differentiation based upon either horizontal or vertical product differentiation. Models of horizontal product differentiation have been based upon alternative specifications of consumer choice - either the Dixit-Stiglitz 'love of variety' (Dixit and Stiglitz 1977) or the Lancaster 'ideal variety' approach (Lancaster 1979). As far as international trade is concerned however, the comprehensive treatment by Helpman and Krugman (1985) suggests that they both lead to similar results. With increasing returns at the level of the firm in models of monopolistic competition, the increasing market size is generally associated with enhanced consumer welfare as the number of varieties expands and (under certain conditions) consumer prices fall. A rather different tradition stems from the 'location' models attributable to Hotelling (1929) where products differ only in terms of location and hence the cost of transportation to different consumer locations. In these models, increased competition and entry may have the contrary effect of eliminating consumer surplus through price discrimination (for a review of the issues see Dorward 1982). This approach seems to be less relevant in the current context. Models based upon vertical differentiation, where richer consumers favour higher quality products, have also featured in the literature. Again rather different results from the monopolistic competition may prevail. As shown by Gabszewicz et al (1981) for example, increasing price competition as engendered by international trade may reduce variety, as lower quality varieties are eliminated. Despite the diversity of outcomes suggested by alternative models,

\footnotetext{
${ }^{1}$ We thank an anonymous referee for raising this possibility.
} 
the monopolistic competition model seems to be the appropriate choice for many sectors of advanced economy manufacturing where fixed costs are non-negligible, and are often (as in the case of R\&D expenditures) specifically directed at product differentiation. At the same time there is considerable competition. From the empirical side, the weight of evidence suggests the importance of aggregate market size in generating intra-industry trade (for a discussion of the evidence, see Grimwade 2000). Moreover the study by Greenaway et al (1995), which specifically attempts to distinguish between intra-industry trade based upon vertical and horizontal differentiation, suggests that it is the "large numbers" model (i.e. competitive market structures) which "seems most appropriate in explaining intra-industry trade" (p. 1512). We therefore feel justified - for both theoretical and empirical reasons - in concentrating on the monopolistic competition model where goods are differentiated horizontally. While the Greenaway et al study notes the empirical importance of vertical product differentiation for UK intra-industry trade, it needs to be noted that their empirical analysis is based on all trade, including trade with developing countries, which is likely to be vertically differentiated (see for example Temple (1998). The empirical analysis in the current paper is however based on bilateral trade flows between developed economies, almost certainly reducing the significance of vertical product differentiation, and the relevance of more traditional comparative advantage models of trade such as that advocated by Falvey (1981) based on perfectly competitive market structures. Moreover, research based on the 'Helpman equation' appears to confirm fully the relevance of the monopolistic competition model for trade between developed economies - as in our analysis here (Debaere 2005). In the light of these considerations, as well as its predominance in the literature on intra-industry trade, which partly reflects its analytical tractability, we consider the monopolistic completion as the appropriate vehicle for our theoretical model which follows. 


\section{A Model of Measurement and Intra-Industry Trade}

In this section we present a general equilibrium model where one sector competitively produces a homogeneous good and the other is monopolistically competitive, allowing us to consider competitive advantage, in the form of product differentiation. Our model is similar to that of Lawrence and Spiller (1983) which extended the foundations laid by Krugman (1979) and Helpman (1981) but introduces the idea of a 'measurement-infrastructure' as discussed above, and which creates a public good effect, reducing the costs each firm incurs in product differentiation. Howeover, making use of the measurement infrastructure (in for example implementing a standardized test procedure to measuring a particular product characteristic) incurs costs in the form of associated investments (for example in instruments), in what we call 'measurement capital'. Using this framework we establish three propositions. First, in a closed economy, there is a positive relationship between the strength of the public good effect on the number of varieties. Second, increased variety is associated with falling prices. Third, the opening up trade between two countries benefits both in that the overall volume of trade between them is bigger than in the absence of a measurement infrastructure. Hence intra-industry trade increases with measurement infrastructure but only up to a certain threshold - beyond which it is not optimal for firms to deploy more measurement capital. To establish these propositions, we first consider the closed economy case.

\section{1 A Closed Economy}

To consider consumption patterns, consider a representative household maximizing utility according to the Dixit-Stiglitz (1977) 'love of variety' utility function with two types of good $Y$ and $X$ :

$$
U=Y^{1-s}\left(\sum_{i=1}^{n} X_{i}^{\theta}\right)^{s / \theta} ; s<1 ; 0<\theta<1
$$

Total utility is a Cobb-Douglas function formed from consuming a homogeneous good $Y$, 
and a differentiable good $X$ produced in n varieties, indexed by $i$ and forming the sub-utility function in the brackets; s and $\theta$ are parameters, with the latter related to the elasticity of substitution, $\sigma$, between any pair of $X_{i}$, by $\theta=(\sigma-1) / \sigma$.

Each household obeys a budget constraint,

$$
I=\sum_{i=1}^{n} P_{i} X_{i}+Y
$$

where income, $I$, is spent on the purchase of the $i$ differentiated goods with their respective prices, $P_{i} ; Y$ is the numeraire. Maximizing (1) subject to (2) and with respect to $X_{i}$ and $Y$ yields, by standard methods:

$$
P_{i}=\frac{s Y X_{i}^{\theta-1}}{(1-s) \sum_{i}^{n} X_{i}^{\theta}}
$$

The price elasticity of demand for each of the differentiated goods is given by $1 /(\theta-1)$ for large $n$. Imposing symmetry across households so that they purchase goods in equal quantities, i.e., $X_{i}=X$ allows us to re-write (3) as:

$$
P=\frac{s Y}{(1-s) n X}
$$

This indicates that an increasing number of varieties reduces the willingness to pay for any given variety.

Firms produce goods from private inputs. For the homogenou good $Y$ this is done via a CobbDouglas production function given by:

$$
Y=K_{Y}^{\varepsilon} L_{Y}^{1-\varepsilon} \quad 0<\varepsilon<1
$$

where $L_{Y}$ and $K_{Y}$ are inputs of labour and capital. Note that the homogenous good does not need any measurement capital. The firms take $w$ and $r$ - the unit cost of labour and capital respectively - 
as given, so that the profit maximization for a firm producing $Y$ leads to the usual $\mathrm{MR}=\mathrm{MC}$ conditions:

$$
\begin{aligned}
& \varepsilon Y=r K_{Y} \\
& (1-\varepsilon) Y=w L_{Y}
\end{aligned}
$$

In the differentiated goods sector each variety $i(i=1, \ldots, \mathrm{n})$ is produced by a single firm which has some monopoly power over its particular variety, but each firm is a price taker in input markets. These firms also make use of the measurement infrastructure, indexed by $0 \leq G<1$ - which captures the extent to which the infrastructure can be accessed by firms in production or marketing. For a firm using negligible measurement infrastructure, $G=0$. The use of the measurement infrastructure however incurs capital costs (which involve additional expenditures required to conform to a given standard, e.g. through the purchase of instruments). There are therefore both benefits and costs in using the measurement infrastructure. The public good effect of the infrastructure is therefore to reduce conventional costs (e.g. in marketing). Using it however requires specific investments for measuring and testing equipment, technical documentation etc. described by a 'translator' function $Z(G)$, which indicates required quantities of measurement capital for a chosen level of $G$. We make three plausible assumptions about this function. First, firms in this sector must make use of a minimum amount of measurement capital (even when $G=0$ ) implying $Z(0)>0$. Second, greater use of the measurement infrastructure requires greater investment in measurement, i.e. $Z^{\prime}(G)>0$. We finally assume that the rental price of measurement capital equals that of conventional capital. We can therefore write the cost function for the production of $X_{i}$ as:

$$
T C_{i}=(1-G)^{\alpha}\left[r \gamma+w \beta X_{i}\right]+\mathrm{rZ}(\mathrm{G}), \alpha>1 ; 0 \leq G<1 ; Z^{\prime}(G)>0
$$

The term in the square bracket on the right-hand-side gives the total cost of employing the conventional inputs of capital and labour, made up of the fixed cost of employing capital, based on a rental price $\mathrm{r}$ and capital outlay $\gamma$, and the variable cost of labour founded on a simple production 
function:

$$
X_{i}=\frac{1}{\beta} L_{i},
$$

where $1 / \beta$ is the marginal product of labour.

The term $(1-G)^{\alpha}$ in $(7)$ indicates that by use of the measurement infrastructure $G$ the firm is able to reduce primary input costs, but since the parameter $\alpha>1$ there are diminishing returns to its use. The condition $G<1$ ensures that firms cannot do away entirely with conventional inputs. The second term on the right-hand-side in (7) is the cost of measurement capital evaluated at $r$. Note that when $G=0$ there is no public good effect, and the model collapses to that of Lawrence and Spiller (1983).

The profit maximizing condition requires that $\mathrm{MR}=\mathrm{MC}$. By substituting the marginal costs from the total cost function, we obtain the following pricing equation for $X_{i}$ :

$$
\frac{P}{w}=\frac{(1-G)^{\alpha} \beta}{\theta}
$$

The optimal price is independent of competing varieties but is positively affected by the wage rate. Additionally (9) leads to our first proposition ${ }^{1}$ :

\section{Proposition 1}

Measurement infrastructure enhances household welfare by reducing the mark-up on wages. This results from the cost-saving affect of measurement infrastructure on biring conventional factors of production.

It is important now to consider the impact of measurement infrastructure on product diversity.

With sufficiently large $n$, entry will ensure zero profits, so the output produced by the

\footnotetext{
${ }^{1}$ See Mathematical Appendix section 1
} 
representative firm using (9) is therefore':

$$
X_{i}=\frac{r \theta \gamma}{\beta w(1-\theta)}+\frac{r \theta Z(G)}{\beta w(1-G)^{\alpha}(1-\theta)}
$$

Equation (10) suggests fixed costs dominate variable costs and so firm/plant size increases with the factor price $(r / w)$ ratio. Both capital outlays $(\gamma)$ and measurement capital $(Z(G))$ increase firm size. However, a marginal improvement in measurement infrastructure $G$, increases firm size only when the marginal benefit, in the form of lower variable costs, exceeds the marginal costs associated with greater measurement capital. To proceed we need to consider the overall size of the economy, and suppose that overall factor endowments are fixed at $\bar{K}$ and $\bar{L}$, so full employment ensures that:

$$
\begin{aligned}
& \bar{L}=L_{Y}+n L_{x} \\
& \bar{K}=K_{Y}+n \gamma
\end{aligned}
$$

where $L_{Y}, K_{Y}, L_{X}, n \gamma$ denote the amounts firm of labour and capital used in the production of $\mathrm{Y}$ and the differentiated good respectively.

Using (6), (9), (10), and (11) we can now obtain the extent of product diversity in the economy as ${ }^{2}$ :

$$
n=\frac{\bar{K} s(1-\theta)}{\gamma\left[\varepsilon(1-s)(1-G)^{\alpha}+s(1-\theta)\right]+Z(G) \varepsilon(1-s)}
$$

This shows that product variety is positively related to capital endowments but negatively to conventional capital outlays (the term on the left hand side of the denominator) as well as measurement capital. Moreover specifying the functional form $Z(G)=Q+F G$ it is possible to

\footnotetext{
${ }^{1}$ See Mathematical Appendix section 2
}

2 See Mathematical Appendix section 3 
show that $\mathrm{dn} / \mathrm{dG}>0$ and $\frac{d^{2} n}{d G^{2}}<0.1$

Using (12) and differentiating with respect to $G$, the first-order condition for obtaining the maximum value for $n$ is,

$$
\alpha \gamma(1-\mathrm{G})^{\alpha-1}=\mathrm{F}
$$

This condition says that the firm should increase its use of measurement infrastructure and invest in measurement capital until the marginal costs of doing so outweigh the marginal benefits. The lefthand-side in (13) is the marginal benefit from increasing the measurement infrastructure in the form of the reduction in the cost of investment on capital outlays and is governed by the parameter $\alpha$. The concavity between the pair $(n, G)$ arises because $\alpha>1$. The right-hand-side is the marginal cost of installing measurement capital for a given level of measurement infrastructure. By inverting

(13) we obtain the underlying measurement infrastructure $G^{*}=1-(F / \alpha \gamma)^{\frac{1}{\alpha-1}}$ that maximizes product diversity. Note that for (13) to hold, the optimum level of measurement infrastructure and capital outlays have to move in the same direction. We therefore can state our second proposition.

\section{Proposition 2}

In equilibrium, the marginal benefit of an extra unit of measurement infrastructure, in the form of a cost reduction in capital outlays, is equal to its marginal cost.

Intuitively, although the relationship between the product diversity and measurement infrastructure is concave, it seems likely that actual observations of the pair $(n, G)$ would display a positive correlation, as indeed we find in the empirical section. Not least, this is because of the public good nature of the measurement infrastructure which suggests its under-provision. However it is a possibility that some countries provide sufficient $G$ to be on the downward sloping part of the

\footnotetext{
${ }^{1}$ See Mathematical Appendix section 4
} 
curve, so ultimately this is an empirical matter. The extent of provision in Sweden - is a case in point (see figure 2).

\section{2 The Open Economy}

We now consider trade between two economies - Home and Foreign - which are identical in terms of technologies and household behaviour. The utility function of a typical consumer in a given country is:

$$
U=\bar{Y}^{1-s}\left(\sum_{i=1}^{n} \bar{X}_{h i}{ }^{\theta}+\sum_{i=1}^{n^{*}} \bar{X}_{f i} \theta\right)^{s / \theta}
$$

where the asterisk $\left(^{*}\right)$ refers to the foreign country; bars refer to the consumption of each good; the subscripts $h$ and $f$ denote home and foreign production respectively. Assuming that varieties produced in home and foreign countries are $\mathrm{n}$ and $\mathrm{n}^{*}$, then goods market equilibrium in a given country implies that the value of consumption of Home and Foreign products equals the value of production, balancing trade:

$$
P_{h} n \bar{X}_{h}+P_{f} n^{*} \bar{X}_{f}+\bar{Y}=P_{h} n X+Y
$$

Using the first-order conditions from utility maximization, imposing symmetry in outputs and prices, and profit maximization across monopolistically competitive firms gives the inverse demand equation:

$$
P=\bar{Y} \frac{s}{(1-s)\left(n+n^{*}\right) \bar{X}}
$$

This is similar to the closed economy case (9). Profit maximization problem in the competitive sector yields the price for capital and labour analogously to (6) for both countries. Finally, the zero profit condition implies that the output supplied in each country in the differentiated goods sector is 
similar to that of (10) assuming that both countries enjoy similar levels of measurement infrastructure (see below).

\subsection{International Trade}

Turning to international trade, we follow Lawrence and Spiller (1983) in allowing countries to differ in terms of both overall size and capital-labour ratio. These relations can be specified by:

$$
\bar{K}^{*}=a \lambda K \quad \bar{L}^{*}=(2-a) \lambda L \quad 0 \leq a \leq 1 \text { and } \lambda>0
$$

where the term $a$ is a measure of the capital-labour differential and $\lambda$ is a measure of the size of the foreign country relative to the home country. World capital and labour stock can now be defined as:

$$
\begin{aligned}
& K_{W}=\bar{K}+\bar{K}^{*}=(1+a \lambda) \bar{K} \\
& L_{W}=\bar{L}+\bar{L}^{*}=(1+(2-a) \lambda) \bar{L}
\end{aligned}
$$

The international capital-labour ratio is independent of measurement infrastructure and is given by

$$
\bar{k}=\delta k, \quad \delta=\frac{[1+a \lambda]}{[1+(2-a) \lambda]}
$$

Where $k$ denotes the capital-labour ratio of the home country. The labour and capital endowment constraints for firms in each country and for each industry are

$$
\begin{aligned}
& \bar{L}=L_{Y}+n X \beta, \\
& \bar{L}^{*}=L_{Y}^{*}+n^{*} X^{*} \beta, \\
& \bar{K}=K_{Y}+n \gamma, \\
& \bar{K}^{*}=K_{Y}^{*}+n^{*} \gamma, \\
& G_{f}=G_{h}=G .
\end{aligned}
$$

The interpretation of the constraints is similar to before. However, the last condition assumes that both countries have similar levels of measurement infrastructure. This simple formulation is intended to display important features of European markets where - in principle - firms in different 
countries have access to similar measurement infrastructures ${ }^{1}$.

\subsection{Trade Volumes}

To find the relationship between infrastructure and trade, we first consider the volume of trade in

differentiated goods. To obtain outputs, we substitute the international wage, rental-cost-of-capital and capital-labour ratios in $(10)^{2}$ :

$$
\begin{aligned}
& X=X^{*}=\left(\frac{\theta \gamma}{\beta(1-\theta)}+\frac{\theta Z(G)}{\beta(1-G)^{\alpha}(1-\theta)}\right) \frac{1}{\varphi \bar{k}}, \\
& \varphi=\frac{\left[s \theta+(1-\varepsilon)(1-s)(1-G)^{\alpha}\right]\left[\gamma(1-G)^{\alpha}+Z(G)\right]}{(1-G)^{\alpha}\left\{\gamma\left[s(1-\theta)+\varepsilon(1-s)(1-G)^{\alpha}\right]+Z(G) \varepsilon(1-s)\right\}}
\end{aligned}
$$

As under autarchy, the size of firms producing the differentiated good increases with the level of measurement infrastructure only when the marginal benefit outweighs the direct marginal cost of investment in measurement capital.

Using the total number of differentiated goods in the world along with home country's share of world income given by, $\pi=z \bar{K} /\left(\bar{K}+\bar{K}^{*}\right)+(1-z) \bar{L} /\left(\bar{L}+\bar{L}^{*}\right)$, where $0<z<1$ is the capital share of income, the post-trade level of consumption in industry $X$ is given by ${ }^{3}$

$$
\bar{X}=\frac{\theta \bar{L}[z+(1-z) \delta]\left[\gamma(1-G)^{\alpha}+Z(G)\right]}{\varphi \delta \beta(1-G)^{\alpha} \bar{K}(1-\theta)(1+a \lambda)}
$$

The trade surplus obtained by subtracting equation (22) from (21) simplifies to:

\footnotetext{
${ }^{1}$ Many features of our model share are similar to those of Lawrence and Spiller (1983). For example the total number of varieties produced in the world is the same in either open or autarchic equilibria - holding constant the level infrastructure G. Therefore, there are no firm exit effects when markets integrate. However, the distribution of the production of varieties depends upon capital intensities between countries hence the initial pattern of comparative advantage.

2 See Mathematical Appendix in section 5.

${ }^{3}$ See Mathematical Appendix section 6.
} 


$$
\begin{aligned}
& \Delta X=X-\bar{X} \\
& =\frac{\theta}{(1-\theta)} \frac{\gamma}{\beta} \frac{1}{\varphi \delta k}\left\{\frac{\gamma(1-G)^{\alpha}(1+a \lambda)+Z(G)(1+a \lambda)-[z+(1-z) \delta]\left[\gamma(1-G)^{\alpha}+Z(G)\right]}{(1-G)^{\alpha}(1+a \lambda)}\right\}
\end{aligned}
$$

The next step is to find out what happens to this trade surplus at different levels of measurement infrastructure. To simplify matters, let both economies have the same size so that $a=\lambda=\delta=1$ and assume there are no endowment advantages. Furthermore, assume the functional form $Z(G)=Q+F G, Z(0)=Q$, for which the level of measurement infrastructure that maximizes $n$ is given by $G^{*}=1-\left(\frac{F}{\alpha \gamma}\right)^{\frac{1}{\alpha-1}}$. Now let us numerically compare the trade surplus at two values of $\mathrm{G}$ : the optimal $G^{*}$ and $G=0$ (i.e., the minimum required infrastructure):

$$
G^{*}: \Delta X=\frac{\theta}{2(1-\theta)} \frac{1}{\beta k} \frac{\gamma\left[s(1-\theta)+\varepsilon(1-s)(1-G)^{\alpha}\right]+Z(G) \varepsilon(1-s)}{\left[s \theta+(1-\varepsilon)(1-s)(1-G)^{\alpha}\right]}
$$

and

$$
G=0: \Delta X=\frac{\theta}{2(1-\theta)} \frac{1}{\beta k} \frac{\gamma[s(1-\theta)+\varepsilon(1-s)]+\varepsilon Q(1-s)}{[s \theta+(1-\varepsilon)(1-s)]}
$$

The expressions (24) and (25) are only numerically comparable. Therefore, we set values ${ }^{1}$ for the parameters $\gamma=0.50, \varepsilon=0.4, s, \theta, F, G=0.5, Q=3, \alpha=2$ which satisfy the conditions for the optimization. We find that at the level of infrastructure $\mathrm{G}^{*}$ the volume of trade is $72 \%$ bigger between the two countries. Furthermore, holding all constant, a rise in the relative country size also positively affects the trade surplus, $\partial(\Delta X) / \partial \lambda>0$. This leads to our final proposition.

\footnotetext{
1 With the exception of ' $F$ ' and ' $G$ ' the remaining data is taken from Lawrence and Spiller (1983).
} 


\section{Proposition 3}

Compared with the situation where measurement infrastructure is minimal, raising the level of infrastructure towards the level at which varieties are maximised, also raises intra-industry trade between two equally endowed countries.

Intuitively, this result reflects the impact of measurement infrastructure in increasing product diversity and hence intra-industry trade. We now turn to the empirical analysis of the role of infrastructure.

\section{Econometric Analysis}

The theoretical model outlined in the last section suggests that there is a positive relationship between the sophistication of measurement infrastructure, the extent of product variety and hence the level of intra-industry trade (over and above that which is dependent upon the impact of market size). The model assumed the existence of a measurement infrastructure providing a public good but which requires complementary private investments. We argued in section 2 that the extent of this infrastructure may be gauged by the existence of industrial standards related to measurement, as well as through the demand for instruments. Accordingly, the aim of this section is to test whether these empirical counterparts of measurement infrastructure are indeed correlated with the extent of intraindustry trade, across both countries and industries. In addition, the determinants of intra-industry trade in an EU context are of interest in their own right, not least in that a key feature of the Single Market Programme, initiated in 1992, has been the harmonisation of standards across the EU (DTI 2005).

A large number of econometric studies have analysed the determinants of intra-industry trade. In the current context of a study of bilateral trade across a range of industries, the 
determinants can be split into country characteristics which are shared between each pair of trading partners and industry characteristics which favour either intra-industry trade or inter-industry trade through more traditional comparative advantage (e.g. Balassa and Bauwens 1987). Following this approach, a basic regression model can be written down as:

$$
\mathrm{IIT}=\mathrm{F}\left(\boldsymbol{Z}, \boldsymbol{X}_{\mathfrak{p}}, \boldsymbol{X}_{\mathfrak{z}} \varepsilon\right)
$$

Where IIT is a measure of intra-industry trade and $\boldsymbol{Z}$ is a vector of industry characteristics, $\boldsymbol{X}_{\boldsymbol{1}}$ is a vector of shared characteristics across a sub-sample (e.g. a common border), $\boldsymbol{X}_{2}$ a vector of shared characteristics across the whole sample (e.g. the size of the combined market), and $\varepsilon$ an error term.

The most familiar measure of the extent of intra-industry trade is provided by the GrubelLloyd index (Grubel and Lloyd 1975), which for any particular country pair $i, j$ intra-industry trade for any given industry $k$ is given by :

$$
G L_{k}=1-a b s\left(X_{i j k}-M_{i j k}\right) /\left(X_{i j k}+M_{i j k}\right) ; 0<G L_{k}<1
$$

where $G L_{k}$ is the Grubel Lloyd index of industry $k$ at a given level of statistical aggregation. The term $X_{i j k}$ is the value of the exports of product group $k$ from country $i$ to country $j$. Similarly, $M_{i j k}$ is the value of the imports of product group $k$ into country $i$ from country $j$. Evidently, the measure varies between 0 and $1^{1}$. In estimation, the truncation of the Grubel-Lloyd index at 0,1 suggests the logit transformation and the measure of intra-industry trade employed here - (IIT):

$$
I I T=\ln \left(G L_{k}\right)-\ln \left(1-G L_{k}\right) ;-\infty<I I T<\infty
$$

This yields unbiased estimates.

Now consider the role of shared country characteristics. Monopolistic competition models of trade predict market size effects so that the higher the average market size of the two countries trading, the greater will be the extent of intra-industry trade (see section 3 above and also for example Dixit and Norman 1980). Large differences in market size on the other hand, are likely to

\footnotetext{
${ }^{1}$ A value close to 1 indicates that the difference between exports and imports is small in relation to total trade while a value close to zero indicates that most trade in the group is predominantly one-way.
} 
depress the extent of intra-industry trade, since the smaller economy generates fewer varieties. These effects have typically been captured by overall indicators of aggregate market size, usually the logarithm of the average GDP for the two economies and the differences in the logs of their respective GDPs (denoted here by lagdp and $\mathbf{l d i f f g} \boldsymbol{d} p)^{1}$.

Other variables used in studies of intra-industry trade include controls for possible wealth effects, language, common borders and distance. The demand for variety is widely believed to expand with consumer income, and hence the measure of intra-industry trade should be positively correlated with average per-capita incomes. Additionally, differences in per capita incomes may be associated with differences in consumer tastes, e.g. Linder $(1961)^{2}$. Following the literature, we use per capita GDP to measure these effects (the logarithms of both the average and the difference, $\mathbf{l} \_\boldsymbol{p} \boldsymbol{p} \boldsymbol{g} \boldsymbol{d} \boldsymbol{p} \boldsymbol{p}$, Idiff_p_gdpp ). Possible further influences on intra-industry trade include geographical distance (e.g. Balassa and Bauwens 1987) (Idist $)^{3}$. The existence of a common-border or common language may also exert an similar influence (dummy variables $\boldsymbol{c b}$, lang $)^{4}$.

The data used are for bilateral trade between 13 EU countries and for 22 industries for 1998 providing a maximum of 1716 observations. Countries and industries are listed in the Data Appendix, where data summaries and data sources can also be found.

Results of OLS regressions incorporating these shared country characteristics are shown in Table 2. Result sets 1 and 2 show regressions with and without industry dummies. All standard errors reported use the Huber/White sandwich variance estimator which allows for potential

\footnotetext{
${ }^{1}$ Further details on all variables including data sources can be found in the Data Appendix.

2 Alternatively, it has been suggested that differences in per capita incomes reflect supply-side differences in factor endowments - e.g. the capital-labour ratio. The bigger these supply side differences, the greater the role of inter-industry trade in bilateral trade.

${ }^{3}$ While geographical distance is generally believed to be a proxy for transport costs and hence held to be generally trade reducing, it may also be proxying for cultural differences or processing possibilities in industries where bulk or weight is important.

${ }^{4}$ Empirical studies have also considered the role of tariff and other trade barriers, although these should be considerably less important in the context of intra-EU trade and we do not use them. In fact the last observation may well be more general, since differences between economies and societies are almost certainly less distinct in the EU context (especially in the pre-enlargement EU being considered here) than in most empirical studies of intra-industry trade, so that these other controls may also be less important.
} 
heteroscedasticity. The results are very similar to others reported in the literature. The coefficients on both average GDP and average per capita GDP are positive and highly significant. However while the difference in average GDP is negative and significant - in line with the prediction of the monopolistic competition model, we do not find that the difference in per capita GDP (although negative) has any statistically significant impact. This may reflect the fact that these differences are much smaller in a study of the EU (at least prior to enlargement), than in other studies in which per capita income differences are much larger across the sample. The distance and common border variables are signed in line with expectation and significant, but the latter is only significant at the $10 \%$ level. The language dummy is however insignificant in all our results. Column 2 shows the same regression but with a full set of industry dummies. While these are jointly highly significant, there is very little change to the coefficients on shared country characteristics, indicating that the cross-sectional variation by industry is operating more or less orthogonally to the shared country characteristics.

Using GDP to capture market size effects does not allow for the fact that size also has an industrial dimension (typically market size is bigger in Germany than in Italy but Italy may have a bigger market in pasta). Thus a preferred measure of market size is the value of industrial production measured at an industrial level for each of the 22 industries which form our dataset. Accordingly result set (3) provides results with measures of market size which are the logarithms of the average of the value of production of each of the trading partners (lapi) and the difference in the logarithms of their respective levels of production in each industry (Idiffpi). Note however that this reduces somewhat the number of observations available, because these data are not available for all countries. Incorporating these new variables shows that although the inclusion of an industry specific measure of market size is important and reduces the impact of the GDP measure, the latter is not eliminated entirely. Omitted factors, other than simple market size, are apparently correlated with the overall average economic size of the trading partners. 
The results thus far have indicated the importance of industrial characteristics through the use of industry dummies, which as the Table shows are statistically highly significant. What are these industrial characteristics?

First allowance is typically made for heterogeneity within an industry where it is possible that constituent goods are produced with quite different technologies, so that what is actually interindustry trade created by differences in endowment ratios is masquerading as intra-industry trade. This is particularly important given the rather high level of aggregation of our industries. Here we use the logarithm of the number of five digit commodities within each industry (Incomm) to represent heterogeneity. Other industry characteristics leading to intra-industry trade are both more complex in character than the country characteristics and generally harder to measure. In addition to the concept of product differentiability - our main concern here - studies have generally focused on the significance of $\mathrm{R} \& \mathrm{D}$, and (possibly) the impact of market structure, although the sign of the these effects is not always unambiguous. We control for other industrial characteristics using the logarithm of R\&D per person (eurdpers), and a measure of industrial concentration at the EU level derived from Davies and Lyons (1996) - which estimates a Herfindhal index of concentration at the three digit level and which depends on both national levels of industrial concentration and the degree of concentration of production among the EU economies (heu).

The central hypothesis of this section is that product differentiability is linked to the supplyside through the measurement infrastructure as in Proposition 2. We measure cross-industry differences in the importance of this infrastructure using the standards count described in section 2. Arguably, a high standards count for a particular industry may simply reflect the number of different product lines that need to be supported by standards, and indeed, there is a relatively high degree of correlation between the logarithm of the standards count (Ins) and the logarithm of the number of 5-digit commodities within each industry (Incomm). For this reason we use the number of standards normalised by the number of products in each industry as our preferred indicator of the 'public good' effect of measurement standards (Isratio), i.e. the 'intensity' with which standards can 
be applied to the range of goods within the industry. We conducted experiments with both the narrow and broad measures of standards (as described in section 2) but given the high degree of colinearity between them, there is little to discriminate between them, and the results reported here in set (4) use the narrow measure. It can be seen that this variable is positive and significant, indicating that measurement related standards do have an effect on intra-industry trade over and above that provided by market size. The other industrial characteristics we use are also significant. The EU degree of concentration has a strong negative impact on intra-industry trade, while the R\&D intensity of the industry (again at the EU level) has a positive influence.

\section{\{TABLE 2 about here\}}

In addition to the usual controls for country differences discussed above, there remains the possibility that different economies do not have equal access to the measurement infrastructure. Although the standards counted may be all marketed in the all the members of EU, and the harmonisation of standards has been an important element of policy, their relevance may differ from country to country because of differences in (for example) the availability of services related to measurement - technical consultancies and so forth. Here, since as we have argued, the public good effect operates at several levels, no simple measure is possible. Our proxy measure for measurement capital is here that of the total consumption of instruments in each economy (i.e. production less exports plus imports). Ideally we would wish to utilise the intensity of instrument use at the industry level. Unfortunately, there is no way of doing this with existing data. However we can use the data we have for the (logarithm of) average aggregate intensity of instrument use for each economy pair lacinstratio). The fifth set of results shows that including this variable does have a positive coefficient which is significant at the $5 \%$ significance level, providing some evidence that the availability of measurement infrastructure is not the same for all countries. 
A number of additional robustness checks were performed and are reported in Table 3. First, various authors have considered adjustments to the basic Grubel-Lloyd measure for the 'overall' trade balance (for a discussion, see Grimwade 2000), which therefore functions as a 'macroeconomic' factor at the country level. A country with a negative (or positive) overall trade balance for example will bias the Grubel-Lloyd index downward. This suggests that a simple solution is to include a set of country dummies. To accommodate this, the shared country characteristics were dropped. However, as can be seen from result set 1, the influence of the set of industry characteristics was little changed. In particular the impact of standard intensity (Isratio) was nearly identical. The second check was for endogeneity in the standard intensities across industries - it may be that industries with high levels of intra-industry trade generate lots of standards with causation running the other way. Here - reported as result set 2 - a standard Wu-Hausman test of exogeneity was applied, using an 'instrumenting regression' of the suspect variable against a set of exogenous regressors. The test failed to reject the null of no-endogeneity at all conventional significance levels. Finally two checks for possible heteroscedasticity were carried out. Against possible outliers, a robust regression technique - available and implemented via STATA ${ }^{\circledR}$ - was employed and reported as result set 3. Alternatively, heteroscedasticity may arise because of the logit transformation of the Grubel-Lloyd index as suggested by Bergstrand (1983) who recommends the use of weighted least squares $^{1}$. In both cases the results are substantially unaltered, with both standard intensity and instrument use correctly signed and significant.

\section{\{TABLE 3 about here\}}

\section{Summary and Conclusion}

Recent growth theory has suggested that increasing variety is an important aspect of technical change in modern economies. This paper has argued that measurement provides an important way of thinking about such technical change, linking the technology infrastructure to

\footnotetext{
${ }^{1}$ On the basis of the logit transformation of the Grubel Llloyd index, Bergstrand suggests weighting all variables (including the constant term) by $\left((I I T /(1-I I T))^{0.5}\right.$ to avoid heteroscedasticity.
} 
privately profitable investment decisions, many of which serve to increase product variety. Measurement is of course an important input into other aspects of technical change, but the main discussion here is focused on the way in which the infrastructure enables firms to differentiate their output on the basis of measurable product characteristics. Moreover, the theoretical model is limited to the consideration of horizontal differentiation, which in no way denies the importance of vertical types of product differentiation in modern economies.

The paper describes how measurement fits into this infrastructure, from R\&D in metrology, often conducted via National Measurement Institutes, through instrument manufacture and technical testing consultancy, to the use of measurement in industry. An important element in this transmission of knowledge is codified information in the form of measurement related standards technical documents providing information regarding test methods, reference materials etc. - which enable firms to conduct measurements.

The existence of these standards owes much to the public provision of research and development in metrology and to the activities of instrument manufacturers and technical services linked to measurement. The available stock of standards through which measurement can be effectively carried out - especially those originating with national standards bodies - creates a strong public good input to the production activities of firms, effectively supporting networks through which products can be compared, tested, etc, and reducing the costs associated with product differentiation, and which relate to both the fixed costs of entry and the variable costs of production. However, the public good nature of the measurement infrastructure requires complementary private investment in the use of measurement. If this hypothesis is accurate, we would expect product differentiation to be greater when the infrastructure supporting measurement is strong. Much of the theoretical work that considers the relationship between product differentiation has - as its basis - the monopolistic competition model - and our theoretical model extends this approach. 
The theoretical model developed formalises the channel through which a measurement infrastructure can be incorporated into an explanation of the observed patterns of intra-industry trade. The model is perhaps particularly relevant for economies forming the EU because of the emphasis on the harmonization of standards resulting in the creation of a measurement infrastructure which is at least partially common. The model predicts that industries will produce more varieties of product when the public good element is strong; in the context of two economies engaged in trade, it also predicts that the stronger the measurement infrastructure, the greater is intra-industry trade between any two economies.

The empirical model builds upon from the many studies of intra-industry trade that allow for both the shared characteristics between economies and the characteristics of individual industries to influence the extent of bilateral intra-industry trade within the EU. It uses bilateral trade data from the OECD for 22 manufacturing industries and 13 EU economies. Beyond the variables generally considered in that literature - most importantly (and as suggested by the monopolistic competition model) the positive influence of the aggregate size of two economies and the negative influence of the difference in their size - the regression model is augmented by two indicators suggested by the previous discussion of the measurement infrastructure. First, we use a count of measurement related standards across the sample of industries to provide an indicator of the public good element provided by the measurement infrastructure. This is treated as common to all 13 economies. This seems reasonable, since harmonisation of standards across the EU has been an important element of the Single Market Programme. However to allow for possible differences in the extent to which individual economies may effectively have differential access to this infrastructure (e.g. through the activities of NMIs, a strong measurement and testing or instrument industry) our analysis also included a measure of an economy's overall use of instruments. Our econometric results confirmed the relevance of both the variables suggested by the simple monopolistic model but also these additional indicators. In particular, we found a strong positive link between standards and variations in intra-industry trade, confirming the prediction of the 
model. The positive and statistically significant impact of an economy's overall use of instruments however, suggests that that not all countries have equal access to the measurement infrastructure.

The econometric results obtained appear to be robust to various checks, but the statistical correlation between standards variety and trade is of course susceptible to other interpretations, including the possibility that both increase with technological maturity, so it is important to note that the standards measure used here relates to measurement related standards, which we believe are important when technologies are developing and prior to the creation of a dominant design associated with technological maturity. Moreover, technology cycles almost certainly operate at a lower level of aggregation than the empirical analysis conducted here. Clearly however, the question of the typical time pattern for the generation of different types of standards is an important question for future research.

\section{Acknowledgements}

This paper has benefited from the advice and inspiration of numerous people, including two anonymous referees Peter Swann of Nottingham University Business School and Ray Lambert of the Department for Business Innovation and Skills (BIS) London must however be singled out for mention.

\section{References}

Balassa, B., Bauwens, L. (1987), Intra-industry specialisation in a multi-industry and multi-country framework. Economic Journal, 97, pp. 923-939.

Bergstrand, J. H. (1983), Measurement and the determinants of intra-industry international trade. In P. K. M. Tharakan (Ed.) Intra-industry trade. Amsterdam: North Holland.

Besen, S.M., Farrell, J. (1994), "Choosing How to Compete: Strategies and Tactics in Standardization” Journal of Economic Perspectives, 8(2), pp. 117-131

Blind, K. (2001), The Impacts of of Innovations and Standards on Trade of Measurement and Testing Products: Empirical Results of Switzerland's Bilateral Trade Flows with Germany, France and the UK. Information Economics and Policy, 13, pp. 439-460. 
Blind, K. (2004), The Economics of Standards: Theory, Evidence, Policy. Cheltenham: Edward Elgar.

Blind, K., Jungmittag A (2005), Trade and the impact of innovations and standards: the case of Germany and the UK. Applied Economics, 2005, 37, pp. 1385-1398.

Chen, N. (2004), Intra-National Versus International Trade in the European Union: Why Do National Borders Matter? Journal of International Economics, 63, pp. 93--118.

David, P.A. (1975), Clio and the Economics of QWERTY, American Economic Review, 75(2), pp. $332-$ 337

Debaere, P. (2005) "Monopolistic competition and trade, revisited: testing the model without testing for gravity", Journal of International Economics, 66, pp. 249-266.

Dixit, A., Stiglitz, J. E. (1977), Monopolistic Competition and Optimum Product Diversity. American Economic Review, 67, pp. 297-308.

Dixit, A., Norman, V. (1980), Theory of International Trade. Cambridge: Cambridge University Press.

Dorward, N (1982) Recent developments in the analysis of spatial competition and their implications for industrial economics, Journal of Industrial Economics, 31(1/2), pp. 131-151

DTI (2005), The Empirical Economics of Standards. DTI Discussion Paper No 12. London: Department of Trade and Industry.

Davies, S.W., Lyons, B. (1996), Industrial Organization in the European Union. Oxford: Oxford University Press.

Falvey, R. (1981) 'Commercial policy and intra industry trade.' Journal of International Economics, vol. 11, pp. 495-511

Farrell, J., Saloner, G. (1985), Standardization, compatibility, and innovation, Rand Journal of Economics, 16, (1), pp. 70-83

Farrell, J., Simcoe, T. (2009), Choosing the Rules for Consensus Standardization Electronic copy available at: http://ssrn.com/abstract $=1396330$

Gabszewicz, J.J., Shaked, A., Sutton, J., and Thisse, J.-F. (1981) International Trade in Differentiated Products, International Economic Review, 22(3), pp. 527-534

Grimwade, N. (2000), International Trade: new patterns of trade, production and investment. 2nd edition, London: Routledge.

Grubel, H.G., Lloyd, P. J. (1975), Intra-Industry Trade: The Theory and Measurement of International Trade in Differentiated Products. London: Macmillan.

Helpman, E. (1981), International Trade in the Presence of Product Differentiation, Economies of Scale and Monopolistic Competition: a Chamberlin-Heckscher-Ohlin approach. Journal of International Economics, 11, pp. 305-340. 
Katz, M.L., Shapiro, C. (1985), Network Externalities, Competition and Compatibility, American Economic Review, 75(3), pp. 424 - 440.

Kindleberger, C.P. (1983), Standards as Public, Collective, and Private Goods, Kyklos 36, pp. 377396

King, M., Lambert, R., Temple, P., Witt, R. (2005), Codified Knowledge and the Impact of the Measurement Infrastructure on Innovation in the UK. Paper Presented to the CIS User Group, Department of Trade and Industry July (DTI).

Krugman, P. (1979), Increasing Returns, Monopolistic Competition, and International Trade. Journal of International Economics, 9, pp. 469--479.

Lancaster, K.J. (1979) Variety, Equity, and Efficiency Oxford: Oxford University Press

Lawrence, C., Spiller, P. T. (1983), Product Diversity, Economies of Scale, and International Trade. Quarterly Journal of Economics, 98, pp. 63-83.

Linder, S.B. (1961), An Essay in Trade and Transformation. New York: Wiley.

Nelson, R.R.. ed. (1993), National Innovation Systems: a Comparative Analysis. New York: Oxford University Press.

NIST (2007), Economic Impact of Measurement in the Semiconductor Industry, Final Report commissioned by Gregory Tassey, National Institute for Standards and Technology, December, http://www.nist.gov/director/planning/upload/report07-2.pdf, Accessed 15/05/2010

Simcoe, T. Standard Setting Committees (2008) http://ssrn.com/abstract $=899595$, accessed $31 / 3 / 2010$

Stern, S., Porter, M., Ferman, J. (2000), The Determinants of National Innovative Capacity. National Burean of Economic Research Working Paper 7876.

Swann, G.M.P., Temple, P., Shurmer, M. (1996), Standards and Trade Performance: the UK Experience. Economic Journal, 106, pp. 1297-1313.

Swann, G.M.P. (1999), The Economics of Measurement. In Report for Department of Trade and Industry, National Measurement System Policy Unit.

Swann, G.M.P. (2000), The Economics of Standardization. In Report for Department of Trade and Industry, Standards and Technical Regulations Directorate, p.90.

Tassey, G. (2000), Standardization in Technology Based Markets, Research Policy, 29(4), pp. 587-602.

Tassey, G. (2004), Underinvestment in Public Goods Technologies, Journal of Technology Transfer, 30 (1/2), pp. 89-113.

Temple, P. (1998) "Quality specialisation in UK trade" in T.Buxton, P. Chapman, and P.Temple (eds) Britain's Economic Peformance, London: Routledge 
Temple, P. and Williams, G. (2002) Infra-technology and economic performance: evidence from the United Kingdom measurement infrastructure, Journal of Information Economics and Policy, 14, pp. 435452.

Utterback, J. M. and Abernathy W.J. (1975) "A Dynamic Model of Process and Product Innovation." Omega, 3(6), pp. 639-56.

Williams, G. (2002), The assessment of the economic role of measurements and testing in modern society. Final Report for the European Commission: Brussels. 


\section{Data Appendix}

\section{VARIABLES USED IN ECONOMETRIC ANALYSIS}

1. DEPENDENT VARIABLE (Source: OECD Bilateral Trade Database for 1998)

Logit transformation of the Grubel-Lloyd Index (GL) (identifier IIT):

$$
\text { GL i,j,k = } 1-[\operatorname{abs}(X \mathrm{i}, \mathrm{j}, \mathrm{k}-\mathrm{M} \text { i,j,k)/(X i,j,k }+ \text { Mi,j,k)) }
$$

Where $\mathrm{i}=$ exporting country $1, \ldots .13, \mathrm{j}=$ importing country $1, \ldots \ldots 13, \mathrm{k}=$ industry $1, \ldots . .22$

The index was constructed for the following 13 countries: Austria, Belgium-Luxembourg, Germany, Denmark, Greece, Spain, United Kingdom, France, Finland, Italy, Netherlands, Portugal and Sweden.

The industries used are from the International Standard Industrial Classification Rev 2 (ISIC rev 2) and are all in manufacturing:

Other Manufacturing; Professional Goods; Other Transport Equipment; Aircraft; Motor Vehicles; Shipbuilding \& Repairing; Radio, TV \& Communication Equipment; Electrical Machinery; Office \& Computing Machinery; Non-Electrical Machinery; Metal Products; Non-Ferrous Metals; Iron \& Steel; Non-metallic Mineral Products; Rubber \& Plastic Products; Petroleum Refineries \& Products; Drugs \& Medicines; Chemicals excluding Drugs; Paper, Paper Products \& Printing; Wood Products \& Furniture; Textiles, Apparel \& Leather and Food, Beverages \& Tobacco.

Potentially there are $13 \times 12 \times 22 / 2=1767$ observations

\section{COUNTRY CHARACTERISTICS}

Average level of GDP in each country pair (la_gdpp) The logarithm of average GDP values between two countries (in PPP\$ billion) (Source: OECD National Accounts)

The difference in the value of GDP in each country pair (Idiff_gdpp)The difference in the logarithm of the absolute value of the difference in GDP for each pair of countries (Source: OECD National Accounts)

The value of production by country pair and industry (la_pi)

The logarithm of the arithmetic mean of the value of production by industry for each pair of countries in 1998 (Source: OECD STAN)

The difference in the value of production by country pair and industry (Idiff_pi)

The logarithm of the absolute difference in the value of production between each pair of countries in 1998. (Source: OECD STAN)

The average level of per capita GDP ( $\left.\boldsymbol{l}_{-} \boldsymbol{p} \_\mathbf{g d} \boldsymbol{p} \boldsymbol{p}\right)$. The logarithm of average income per capita for 1998 (measured by GDP/population) between two countries and evaluated PPP\$s as estimated by the OECD. (Source: OECD National Accounts) 
The difference in per capita GDP between trading partners (Idiff_p_gdpp) The logarithm of the absolute different income per capita between two partner countries in 1998 as evaluated in PPP\$ (Source: OECD National Accounts)

The distance between two trading partners in kilometres (ldist). The distances between the cities of corresponding regions are measured by the "great circle distance" formula based on the latitudes and longitude of each city. Therefore, All EU 15 countries are split into 206 regions and all these distances are weighted by their related GDP share calculated by GDPm/GDP, where GDPm is the GDP value of a region and GDP is at the whole country level. (source: Chen 2004)

Common Border $(\boldsymbol{c} \boldsymbol{b})$. A dummy variable $=1$ if the country pair share a common border.

Common Language (lang) A dummy variable $=1$ if the country pair share the same language.

Instrument Consumption Intensity (1a_cinstratio) The logarithm of the average intensity of instrument consumption between two countries with intensity measured by overall instrument consumption deflated by average GDP (Source: Williams (2002) for instrument consumption data by country.

\section{INDUSTRY CHARACTERISTICS}

Industrial Concentration (identifier heu) Source: Davies and Lyons (1996))

This was constructed from an estimate of the Herfindahl Index at the EU level at the three digit NACE classification and aggregated using a geometric mean of the constituent industries.

R\&D intensity (eurdpers) Business expenditure on Research and Development (measured in \$ PPPs for the EU (exc Portugal) in each industry deflated by the aggregate level of employment. Source: OECD ANBERD-Analytical Business Enterprise Research and Development data for 1998 and STAN- STructural ANalysis data for employment)

Industrial Heterogeneity (Incomm) The logarithm of the number of commodity headings at the 5-digit level in each industry ource: Based upon the OECD Databases (ITCS- International Trade by commodity Statistics)

The strength of the measurement infrastructure (Isratio) This is the logarithm of a cross industry count of publicly available standards published in PERINORM(C) which incorporate a reference in their descriptors to both measurement and testing. Specially constructed descriptors were used to allocate standards to each industry. This count has been normalised by the number of commodities in each of the 22 industries (see above) (Source: PERINORMC), King et al (2005)) 


\section{SUMMARY STATISTICS}

TABLE A1

Summary data

\begin{tabular}{|c|c|c|c|c|c|}
\hline Variable & $\begin{array}{r}\text { No of } \\
\text { observations }\end{array}$ & Mean & $\begin{array}{l}\text { Standard } \\
\text { Deviation }\end{array}$ & Minimum & Maximum \\
\hline iit2 & 1695 & 0.38 & 1.85 & -8.93 & 8.90 \\
\hline la_gdpp & 1716 & 6.20 & 0.76 & 4.86 & 7.40 \\
\hline Idiff_gdpp & 1716 & 5.68 & 1.73 & 0.26 & 7.51 \\
\hline la_pi & 1483 & 22.88 & 1.20 & 17.83 & 25.48 \\
\hline Idiff_pi & 1483 & 22.70 & 1.61 & 14.05 & 25.82 \\
\hline$l a \_p \_g d p p$ & 1716 & 9.99 & 0.11 & 9.66 & 10.17 \\
\hline Idiff_p_gdpp & 1716 & 7.81 & 1.22 & 2.83 & 9.39 \\
\hline Idist & 1716 & 7.09 & 0.56 & 5.23 & 8.05 \\
\hline$c b$ & 1716 & 0.15 & 0.36 & 0.00 & 1.00 \\
\hline lang & 1716 & 0.08 & 0.27 & 0.00 & 1.00 \\
\hline la_cinsratio & 1716 & 1.60 & 0.43 & 0.37 & 2.38 \\
\hline heu & 1638 & 0.03 & 0.04 & 0.00 & 0.20 \\
\hline eurdpers & 1716 & 4028.18 & 4783.92 & 145.00 & 17466.00 \\
\hline Incomm & 1716 & 3.99 & 1.36 & 1.61 & 5.97 \\
\hline Isratio & 1716 & 0.97 & 0.97 & -0.76 & 2.83 \\
\hline
\end{tabular}




\section{Mathematical Appendix}

\section{Section 1}

Profit-maximisation requires $\mathrm{MR}=\mathrm{MC}$,

In the model MR, marginal revenue, is $P\left(1-\frac{1}{\eta}\right)$, where elasticity $\eta=\frac{1}{1-\theta}$.

MC, marginal cost, is $\beta w(1-G)^{\alpha}$. Therefore, we can write the profit maximizing condition as $P\left(1-\frac{1}{\eta}\right)=\beta w(1-G)^{\alpha}$. Then we obtain the following pricing equation for $X_{\mathrm{i}}$

$\frac{P}{w}=\frac{(1-G)^{\alpha} \beta}{\theta}$.

The mark-up is therefore dependent upon $G$

\section{Section 2}

The profits the firm receives, $\pi$, can be expressed as:

$\pi=P X-T C$

The first term is total revenue, and the second term is total cost.

Set $\pi=0$, Using equations (7) and (9) in the text we can now obtain

$\frac{(1-G)^{\alpha} \beta w}{\theta} X=(1-G)^{\alpha}\left[r \gamma+w \beta X_{i}\right]+\mathrm{rZ}(\mathrm{G})$

After rearranging equation (M 2.2), we finally obtain equation (10) in the text.

$$
X_{i}=\frac{r \theta \gamma}{\beta w(1-\theta)}+\frac{r \theta Z(G)}{\beta w(1-G)^{\alpha}(1-\theta)}
$$

\section{Section 3}

According to equation (11) in the text, the labour endowment in home country is:

$$
\begin{aligned}
& \bar{L}=L_{Y}+n X \beta=L_{Y}+n \beta X=\frac{(1-\varepsilon)}{w} Y+n \beta X \\
& \bar{L}=\frac{(1-\varepsilon)}{w} \frac{(1-s)}{s} n X P+n \beta X
\end{aligned}
$$

Rearranging, we obtain: 


$$
\bar{L}=n \frac{r}{w}\left\{\frac{(1-\varepsilon)(1-s) \gamma(1-G)^{\alpha}}{s(1-\theta)}+\frac{(1-\varepsilon)(1-s) Z(G)}{s(1-\theta)}+\frac{\theta \gamma}{(1-\theta)}+\frac{\theta Z(G)}{(1-G)^{\alpha}(1-\theta)}\right\}
$$

The capital endowment in home country is:

$$
\begin{aligned}
& \bar{K}=K_{Y}+n \gamma=\frac{\varepsilon}{r} \frac{(1-s)}{s} n X P+n \gamma \\
& \bar{K}=\frac{\varepsilon}{r} \frac{(1-s)}{s} n\left(\frac{r \theta \gamma}{\beta w(1-\theta)}+\frac{r \theta Z(G)}{\beta w(1-G)^{\alpha}(1-\theta)}\right) \frac{(1-G)^{\alpha} \beta w}{\theta}+n \gamma \\
& \bar{K}=n \frac{\gamma\left[\varepsilon(1-s)(1-G)^{\alpha}+s(1-\theta)\right]+Z(G) \varepsilon(1-s)}{s(1-\theta)}
\end{aligned}
$$

After rearranging equation (M.3.6), we obtain equation (12) in the text.

$$
n=\frac{\bar{K} s(1-\theta)}{\gamma\left[\mathcal{E}(1-s)(1-G)^{\alpha}+s(1-\theta)\right]+Z(G) \varepsilon(1-s)}
$$

\section{Section 4}

The parameter restrictions are: $\alpha>1 ; 0<\varepsilon<1 ; 0<s<1,0<\theta<1$ and $0 \leq G<1$ Assuming $Z(G)=Q+F G$, equation (12) in the text becomes

$$
\begin{aligned}
& n=\frac{\bar{K} s(1-\theta)}{\gamma\left[\varepsilon(1-s)(1-G)^{\alpha}+s(1-\theta)\right]+(Q+F G) \varepsilon(1-s)}, \\
& n=\frac{\bar{K} s(1-\theta)}{\varepsilon(1-s)(1-G)^{\alpha} \gamma+s(1-\theta) \gamma+(Q+F G) \varepsilon(1-s)}
\end{aligned}
$$

In order to simplify, let:

$$
\begin{aligned}
& A \equiv \bar{K} s(1-\theta) \\
& B \equiv \mathcal{E}(1-s)(1-G)^{\alpha} \gamma+s(1-\theta) \gamma+(Q+F G) \mathcal{E}(1-s)
\end{aligned}
$$

So equation (M.4.2) becomes

$$
n=\frac{A}{B}
$$


Since $A$ (M.4.3) is not a function of $G$, it can be viewed as a constant. In order to simplify the mathematics, we only need to establish the relationship between $B$ (equation A 2.2) and $G$. Note that $n$ is inversely proportional to $B$, i.e. when $B$ has a minimum point, $n$ has a maximum point and vice versa.

The first and second derivatives of $B$ are:

$$
\begin{aligned}
& B^{\prime}=-\alpha \gamma \mathcal{E}(1-s)(1-G)^{\alpha-1}+\mathcal{E}(1-s) F \\
& B^{\prime \prime}=(\alpha-1) \alpha \gamma \mathcal{E}(1-s)(1-G)^{\alpha-2}>0
\end{aligned}
$$

Since $B "(G)>0 \quad B$ will have a minimum point at the level of $\mathrm{G}$ which maximizes $\mathrm{n}\left(\mathrm{G}^{*}\right.$ in text).

\section{Section 5}

Two steps are needed to obtain the international capital-labour ratio $\bar{k}$; the first is to get the international labour endowment.

According to equations (22) and (24) in the text, the world labour stock is

$$
L_{W}=\bar{L}+\bar{L}^{*}=L_{Y}+n X \beta+L_{Y}^{*}+n^{*} X^{*} \beta
$$

Since all firms are of equal size, $X=X^{*}$, equation (M 5.1) becomes

$$
\begin{aligned}
& L_{W}=\left(n+n^{*}\right) \beta X+\left(L_{Y}+L_{Y}^{*}\right) \\
& L_{W}=\left(n+n^{*}\right) \beta X+\frac{(1-\varepsilon)}{w}\left(Y+Y^{*}\right)
\end{aligned}
$$

After rearranging of Equations (M 5.1) and (M 5.2), international labour endowment is

$$
L_{w}=\left(n+n^{*}\right) \frac{r}{w} \frac{s \theta\left[(1-G)^{\alpha} \gamma+Z(G)\right]+(1-G)^{\alpha}\left\{(1-\varepsilon)(1-s)\left[(1-G)^{\alpha} \gamma+Z(G)\right]\right\}}{s(1-\theta)(1-G)^{\alpha}}
$$

And international capital endowment:

$$
K_{W}=\bar{K}+\bar{K}^{*}=\frac{\varepsilon}{r} Y+n \gamma+\frac{\varepsilon}{r} Y^{*}+n^{*} \gamma
$$

And

$$
K_{W}=\left(n+n^{*}\right) \gamma+\frac{\varepsilon}{r} \frac{(1-s)}{s} X P\left(n+n^{*}\right)
$$

Rearranging, the amount of international capital is therefore: 
$K_{W}=\left(n+n^{*}\right)\left\{\gamma+\frac{\varepsilon(1-s) \gamma(1-G)^{\alpha}+\varepsilon(1-s) Z(G)}{s(1-\theta)}\right\}$

Thus, the international capital-labour ratio $\bar{k}$ is $\bar{k}=\frac{K_{W}}{L_{W}}$

$$
\bar{k}=\frac{\left(n+n^{*}\right)\left\{\gamma+\frac{\varepsilon(1-s) \gamma(1-G)^{\alpha}+\varepsilon(1-s) Z(G)}{s(1-\theta)}\right\}}{\left(n+n^{*}\right) \frac{r}{w} \frac{s \theta\left[(1-G)^{\alpha} \gamma+Z(G)\right]+(1-G)^{\alpha}\left\{(1-\varepsilon)(1-s)\left[(1-G)^{\alpha} \gamma+Z(G)\right]\right\}}{s(1-\theta)(1-G)^{\alpha}}}
$$

Finally,

$$
\bar{k}=\frac{\left[s \gamma(1-\theta)+\varepsilon(1-s) \gamma(1-G)^{\alpha}+\varepsilon(1-s) Z(G)\right](1-G)^{\alpha}}{\left[\gamma(1-G)^{\alpha}+Z(G)\right]\left[s \theta+(1-\varepsilon)(1-s)(1-G)^{\alpha}\right]} \frac{w}{r}
$$

Therefore, the international wage-rental ratio is

$$
\frac{w}{r}=\frac{\left[s \theta+(1-\varepsilon)(1-s)(1-G)^{\alpha}\right]\left[\gamma(1-G)^{\alpha}+Z(G)\right]}{\left.\left[s \gamma(1-\theta)+\varepsilon(1-s) \gamma(1-G)^{\alpha}+\varepsilon(1-s) Z(G)\right](1-G)^{\alpha}\right]} \bar{k}=\varphi \bar{k}
$$

where $\varphi=\frac{\left[s \theta+(1-\varepsilon)(1-s)(1-G)^{\alpha}\right]\left[\gamma(1-G)^{\alpha}+Z(G)\right]}{\left.\left[s \gamma(1-\theta)+\varepsilon(1-s) \gamma(1-G)^{\alpha}+\varepsilon(1-s) Z(G)\right](1-G)^{\alpha}\right]}$

Substituting the international wage-rental ratio into equation (20) we obtain equation (25) in the text.

\section{Section 6}

Assuming that the home country's share of world income is $\pi=z \bar{K} /\left(\bar{K}+\bar{K}^{*}\right)+(1-z) \bar{L} /\left(\bar{L}+\bar{L}^{*}\right)$, consumption of the differentiated good in home country is:

$$
\bar{X}=\pi X=\left[\frac{\bar{z}}{\left(\bar{K}+\bar{K}^{*}\right)}+\frac{(1-z) \bar{L}}{\left(\bar{L}+\bar{L}^{*}\right)}\right] *\left[\frac{r \theta \gamma}{\beta w(1-\theta)}+\frac{r \theta Z(G)}{\beta w(1-G)^{\alpha}(1-\theta)}\right]
$$

On rearranging, total consumption of the differentiated good (equation 26 in the text)

$$
\bar{X}=\frac{\theta \bar{L}[z+(1-z) \delta]\left[\gamma(1-G)^{\alpha}+Z(G)\right]}{\varphi \delta \beta(1-G)^{\alpha} \bar{K}(1-\theta)(1+a \lambda)} \text { can be obtained. }
$$




\section{Figures}

Figure 1

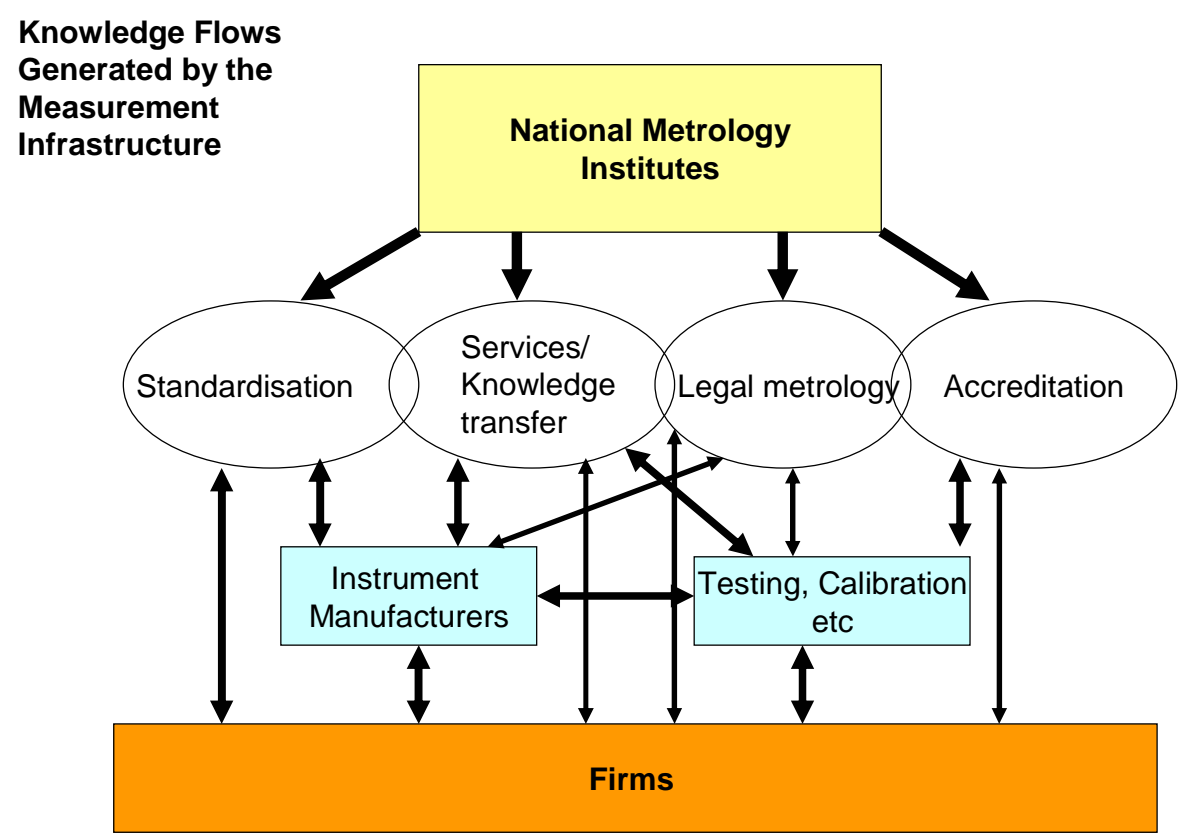


Figure 2

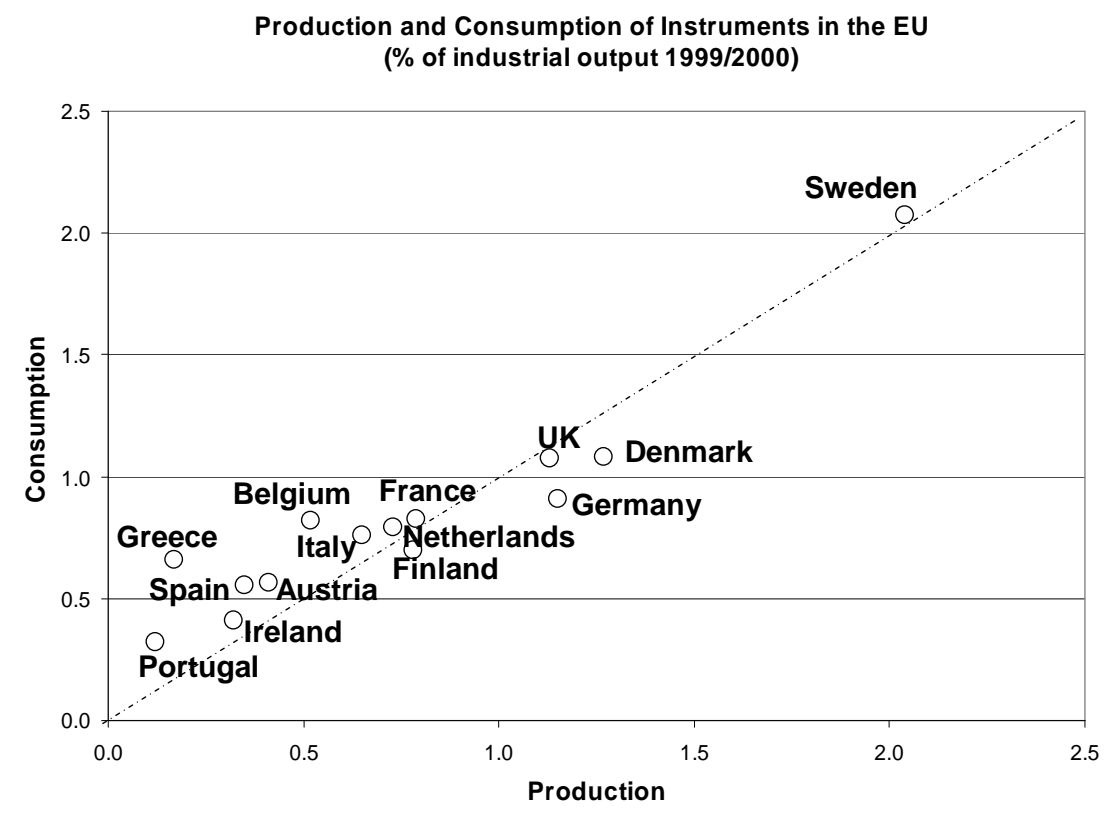

Source: Williams (2002; EUROSTAT) 
Figure 3

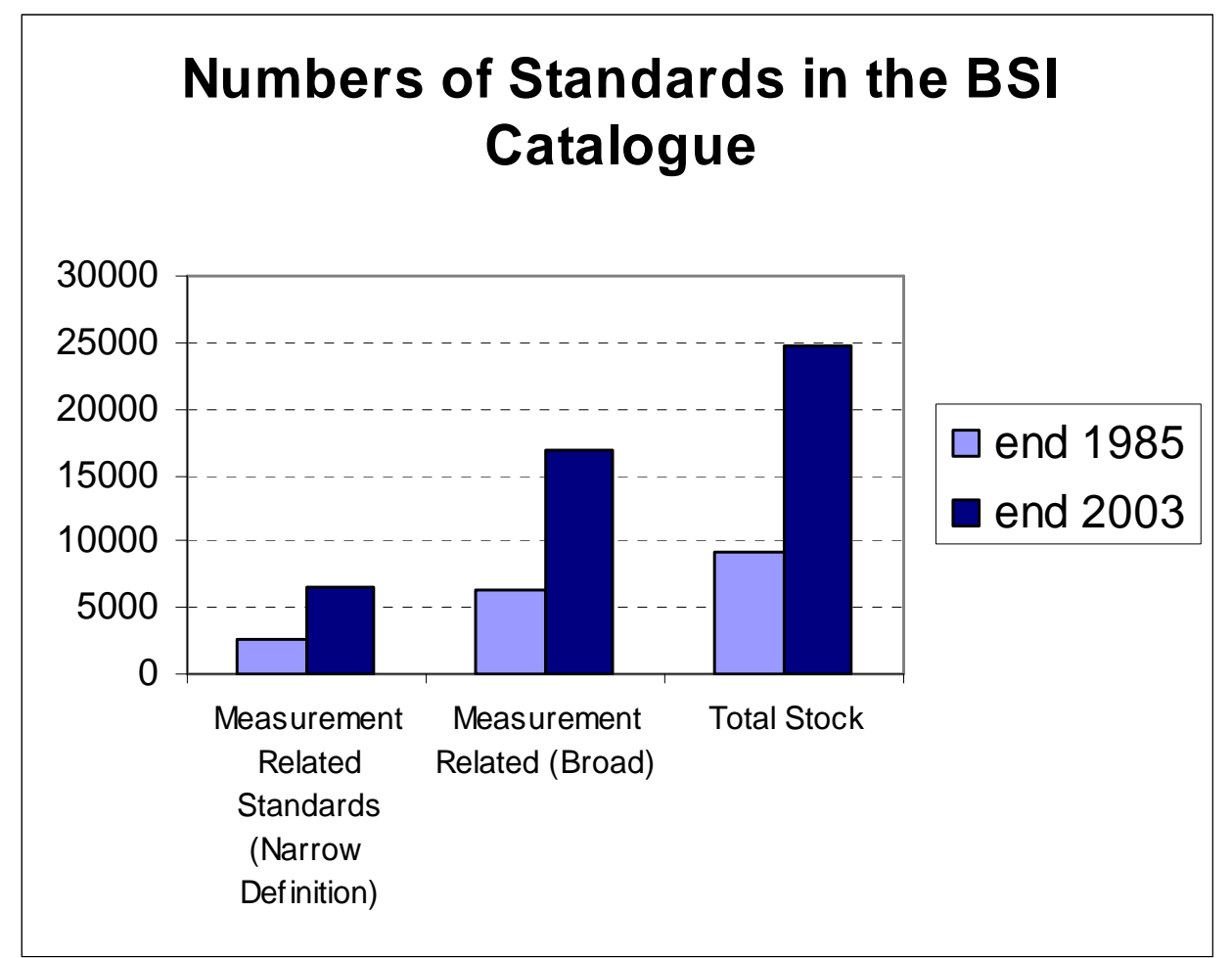

Source: PERINORMC 


\section{TABLES}

\section{Table 1}

\begin{tabular}{llrr} 
& & \multicolumn{2}{c}{ Measurement Related } \\
Industry & & Standards Stocks for 2002 & \\
Number & & Narrow & Broad \\
\hline 1 & & 144 & 378 \\
2 & Other Manufacturing & 918 & 1614 \\
3 & Professional Goods & 53 & 166 \\
4 & Other Transport Equipment & 106 & 561 \\
5 & Aircraft & 114 & 305 \\
6 & Motor Vehicles & 27 & 59 \\
7 & Shipbuilding \& Repairing & 399 & 1160 \\
8 & Radio, TV \& Communication Equipment & 843 & 2194 \\
9 & Electrical Machinery & 27 & 268 \\
10 & Office \& Computing Machinery & 855 & 2408 \\
11 & Non-Electrical Machinery & 347 & 1088 \\
12 & Metal Products & 122 & 221 \\
13 & Non-Ferrous Metals & 92 & 166 \\
14 & Iron \& Steel & 290 & 775 \\
15 & Non-metallic Mineral Products & 215 & 554 \\
16 & Rubber \& Plastic Products & 217 & 357 \\
17 & Petroleum Refineries \& Products & 13 & 38 \\
18 & Drugs \& Medicines & 695 & 1022 \\
19 & Chemicals excluding Drugs & 206 & 412 \\
20 & Paper, Paper Products \& Printing & 52 & 171 \\
21 & Wood Products \& Furniture & 266 & 791 \\
22 & Textiles, Apparel \& Leather & 508 &
\end{tabular}

Source: PERINORMC 
Table 2

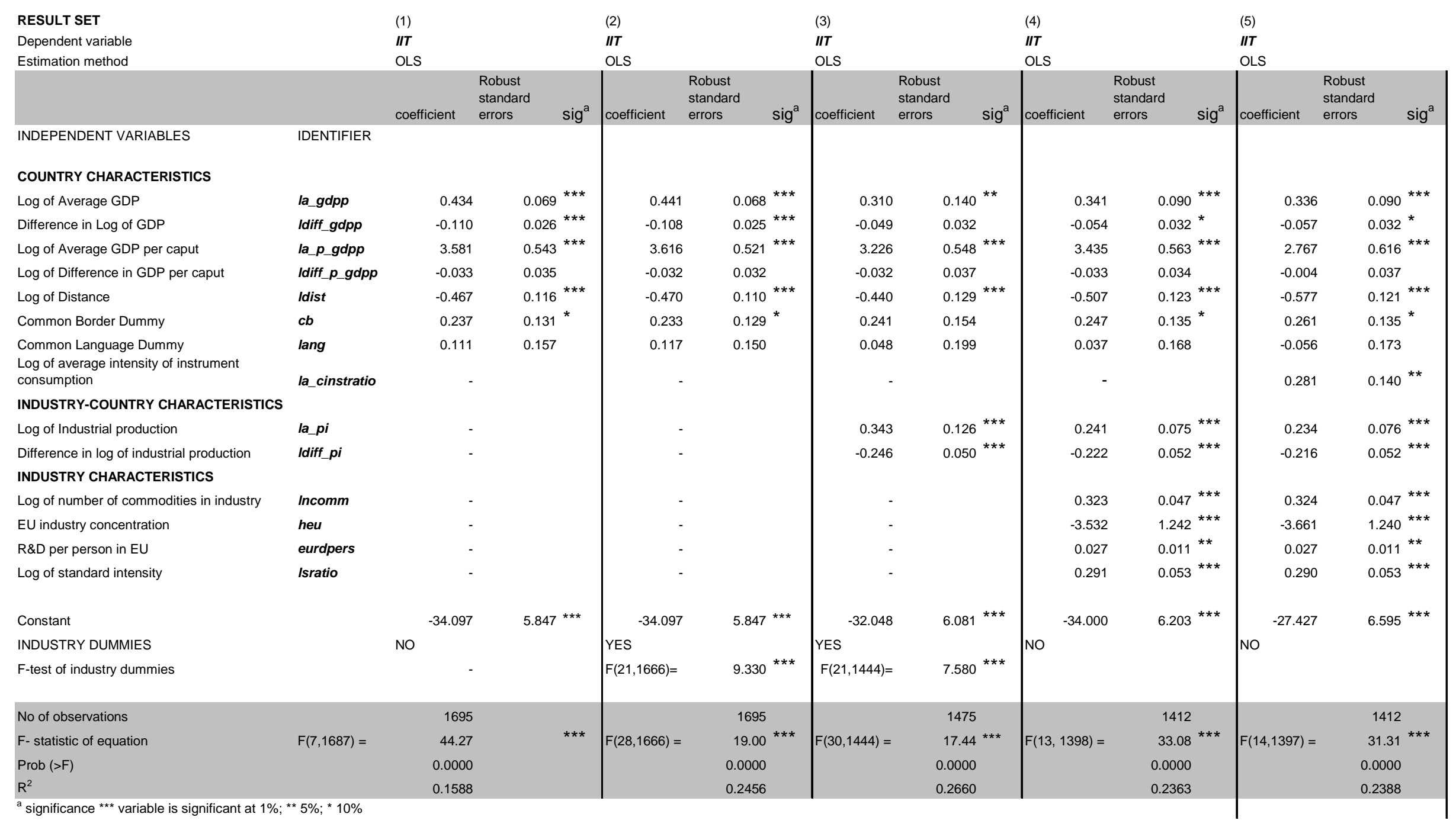


Taking the Measure of Things: the Role of Measurement in EU Trade

\section{Table 3}

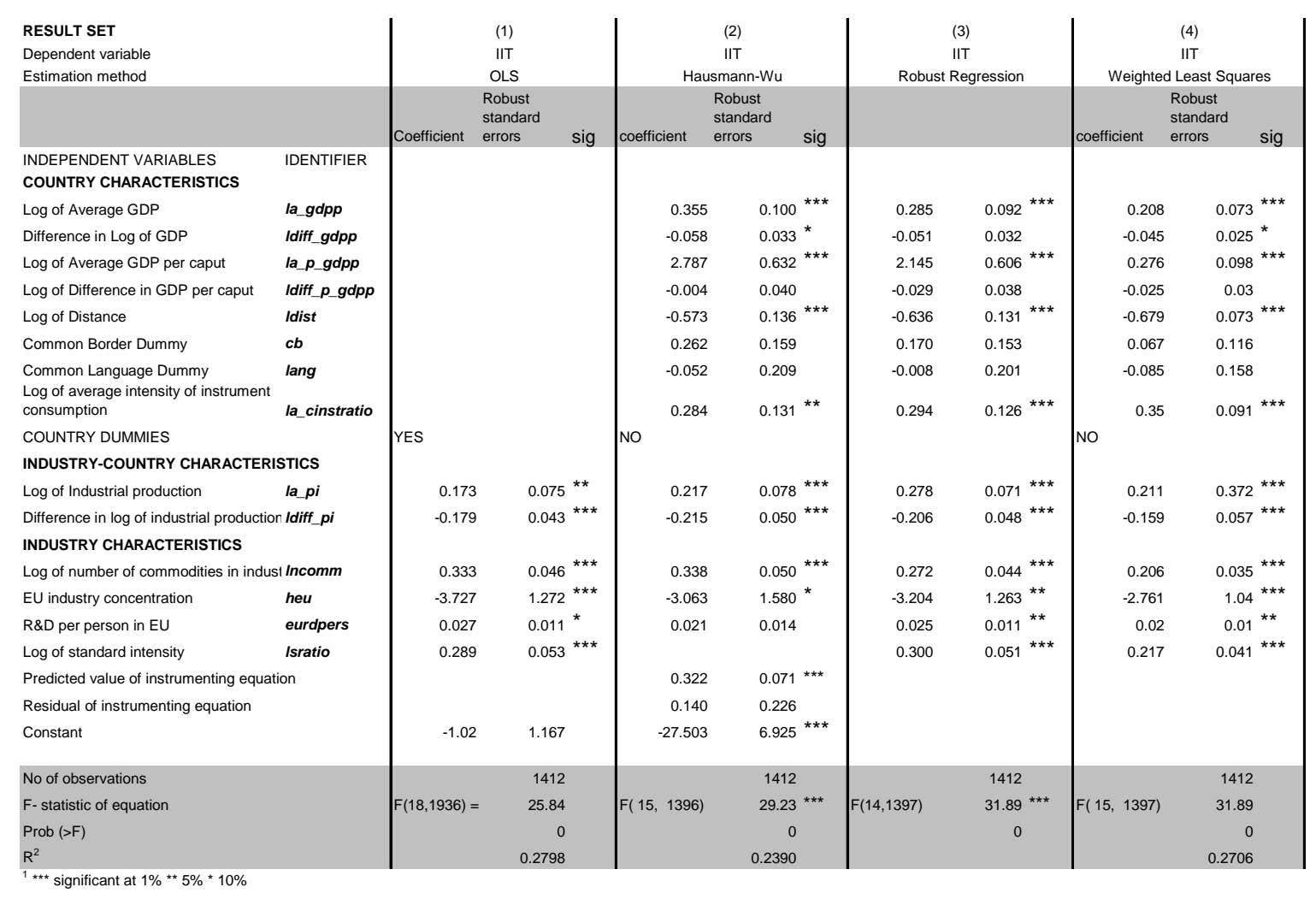

